Marta Libedinsky, Paula Pérez, María Ximena García Tellería (coords.) / Las TIC en la escuela secundaria. Proyectos, consejos y herramientas para la inclusión digital

Reseña por Aurelia García

Praxis educativa, Vol. 20, № 2; mayo-agosto 2016 - ISSN 0328-9702 (impreso) y 2313-934X (en línea), pp. 70-72

DOI: http://dx.doi.org/10.19137/praxiseducativa-2016-200208

\section{Marta Libedinsky, Paula Pérez, María Ximena García Tellería (coords.) \\ Las TIC en la escuela secundaria \\ Proyectos, consejos y herramientas para la inclusión digital \\ Ediciones Novedades Educativas 2015}

S las TIC han siempre enunciado su espíritu colaborativo, es en esta obra que las coordinadoras Marta Libedinsky, Paula Pérez, María Ximena García Tellería lo demuestran indiscutiblemente en nueve capítulos que componen el libro colectivo Las TIC en la escuela secundaria, realizado por miembros del equipo de trabajo y colaboradores de la Fundación Evolución y publicado por la Editorial Noveduc.

Desde el prólogo Susana Alcaraz invita de "Buscar la sorpresa en lo cotidiano"; sorpresas amparadas y determinadas por el marco legal No 26.206 que ayuda a revisar las prácticas y modelos de organización institucional que garanticen derecho a la educación secundaria.

El libro está destinado tanto a equipos de conducción y acompañamiento, como a los docentes disciplinares, dado que la integración de las tIC en el curriculum, desafía a la organización propia de la escuela secundaria y habilita la posibilidad de pensar nuevas configuraciones y estrategias de desarrollo profesional de las/os educadoras/es. El desafío se presenta en este libro a través de nueve capítulos que presentan idéntica estructura y en cada uno se podrán encontrar un apartado dedicado al marco conceptual referido al tema central del capítulo (ideas, preguntas, dilemas, problemas), una crónica o relato de una experiencia didáctica innovadora realizada en las aulas contada en primera persona, consejos ofrecidos por autorizados especialistas en el campo, el testimonio de un profesional que explica cómo las TIC han influido en su vida laboral (periodistas, un investigador, la autora de un blog, una historiadora, una artista plástica, una contadora, un bioquímico, una traductora), y para concluir, una sección con recomendaciones (de libros, sitios web, software, webware, aplicaciones, etc.). Es importante destacar que los primeros cuatro capítulos abordan temas clave transversales y los cinco últimos encaran la relación entre una selección de disciplinas con las tecnologías.

"Modelos 1 a 1" es nombre del capítulo 1q aborda el tema de la introducción de los modelos 1 a 1 en tiempos de innovación y de recientes políticas públicas educativas de implementación de las TIC. La Experiencia: Cómo convertirse en una profesora 2.0 María Marta Tronci presenta a una docente que recibió en su escuela el modelo 1 a 1 y trabaja con sus alumnos en un proyecto interescolar de reciclado; Mónica Bardi brinda consejos para introducir las TIC en las clases y un periodista cuenta cómo las tecnologías están cambiando el periodismo.

En el apartado de Vida cotidiana María Gabriela Ensinck relata: Cómo las tecnologías están cambiando al periodismo. La mirada se hace sobre aquellos modelos que involucran a un estudiante, una computadora $y$ una experiencia de aprendizaje personalizada en un contexto de conexión inalámbrica de acceso continuo a Internet en el marco el andamio de las " 5 C: computadoras, conectividad, contenidos, capacitación y comunidad".

El capítulo 2, "Proyectos colaborativos", aborda el tema de la colaboración, promueve el método de trabajo en proyectos en el nivel secundaria; detalla cinco dinámicas de colaboración útiles para diseñar proyectos y actividades colaborativas: la producción conjunta, la producción en espejo, la producción mosaico, la producción secuenciada y la producción complementaria. Se relata en este mismo capítulo la experiencia del proyecto colaborativo de alcance internacional "Atlas de la diversidad" y brinda consejos para una implementa- 
ción plena y satisfactoria, y un periodista da su testimonio respecto del valor de las tecnologías colaborativas. Se muestra en el enunciado "Vida cotidiana": Las nuevas tecnologías y los medios de comunicación. Omer Freixa

"La investigación escolar y las TIC", se acerca desde el capítulo 3, y explica cómo encarar hoy las investigaciones escolares sumando dispositivos tecnológicos móviles y describe dos estructuras didácticas diseñadas por Bernard Dodge: las WebQuests y los WonderPoints; presenta una experiencia de aula realizada en Rosario (Santa Fe) La investigación en el aula con netbooks y presentada por Gabriela Spado$n i$. Se presentan actividades focalizadas en la búsqueda, análisis, interpretación, selección, evaluación y/o transformación de información tendiente a descubrir o averiguar algo y a comunicarlo. Finalmente se brindan interesantísimos consejos para guiar la lectura y escritura escolar y alerta respecto de cuándo no integrar tecnologías, y el testimonio de un investigador.

En el capítulo 4, Marta Libedinsky y Paula Pérez relatan "Narraciones digitales: para suspender voluntariamente la incredulidad" destacando el valor de la narración como modo de acceso al conocimiento en pie de igualdad con las ciencias; invita a planificar la narración, a combinar el antiguo arte de relatar historias con los recursos multimediales y a realizar una revisión a conciencia antes de elegir el espacio virtual de publicación; presenta una experiencia de taller de historias digitales en inglés referido a Anna Frank y la autora de un blog sobre escenas lectoras cuenta cómo lo mantiene. Los consejos invitan a pensar: Cómo combinar textos narrativos con contenido digital. Ana Carolina López y desde Vida cotidiana: Promoción al paso. El blog Escenas Lectoras. Daniela Azulay.

El capítulo 5 introduce tres preguntas orientadas a indagar el sentido del estudio de la Geografía y la Historia y por qué es importante la introducción de las TIC. ¿Para qué sirve estudiar Historia en la escuela secundaria? ¿Para qué sirve estudiar Geografía en la escuela secundaria? ¿Por qué integrar las TIC en esas dos asignaturas aquí y ahora? Las respuesta se aproximan en este capítulo, "Historia, Geografía y TIC" en el que una docente narra la experiencia de su escuela en la que alumnos de secundario aprenden Historia al enseñarles a los alumnos de primaria; se brindan consejos para realizar actividades con las TIC para comprender procesos históricos y una historiadora describe cómo las TIC modifican el proceso de investigación histórica.

Las TIC en la Historia y geografía muestra algunas razones por las cuales sirve estudiar historia y geografía y integradas a las TIC. Ejemplos de esto son la Historia oral, Videominutos, Ensayos fotográficos, Google MapsStreet View, Líneas de tiempo, Estudios de casos, Una ley, un acontecimiento, un país, una ciudad o Historias locales

Llega el momento, en el capítulo 6, de las "Artes y TIC" en las que se invita a repensar el rol de la imaginación en la enseñanza, el aprendizaje y el currículo de la educación artística mediada por las TIC en las escuelas secundarias; narra la experiencia de implementación del proyecto "Las voces de los jóvenes en Argentina"; sugiere consejos sobre cómo integrar las TIC en la literatura y una artista plástica comparte cómo las TIC están presentes en su profesión. La experiencia cuenta del proyecto "Las voces de los jóvenes en Argentina”. Cristina Bosio Ferrer.

Caemos en cuentas en el capítulo 7, "Matemática y TIC”, con la invitación a reflexionar en torno a los problemas que dificultan la integración efectiva y significativa en el área de Matemática y sugiere posibilidades de integración de la asignatura con otras áreas del conocimiento. Sobre la introducción de las TIC en las clases de Matemática es la experiencia narrada por una docente, asimismo se ofrecen consejos para planificar clases de Matemática con integración de las TIC. En el apartado Vida cotidiana: La tecnología a lo largo del tiempo en la profesión del contador.

"Física, Química, Biología y TIC": El marco conceptual: Misión: aprender y enseñar ciencias brindado por Marta Libedinsky y Paula Pérez ¿Cómo hacer para introducir nociones de difícil comprensión o contraintuitivas en las aulas? ¿Cómo hacer para asegurar que el nuevo contenido disciplinar se sintetice con ese conocimiento previo cuando sean congruentes? ¿Cómo garantizar que el contenido disciplinar más nuevo desplante y suplante estereotipos, prejuicios y errores conceptuales? Sobre las problemáticas que sugieren estas tres preguntas se nos invita a pensar en el capítulo 8. Se presenta la expe- 
riencia de una docente que enseña Biología con las TIC; se ofrecen consejos sobre lo que hay que saber para enseñar Biología; un reconocido bioquímico realiza una síntesis de los principales avances de la Bioquímica en los últimos sesenta años mediados por tecnología. Con la misión: aprender y enseñar ciencias se muestra: "Actualmente vía Internet vamos conociendo novedosos y amenos formatos y plataformas que nos permiten encontrar las respuestas a preguntas que emergen en la vida de todos los días, ver elaborados documentales de divulgación científica, disfrutar de relatos sobre la vida y la obra de los científicos, consultar atractivas infografías, escuchar conferencias TED sobre las ciencias, ver películas de ficción que abordan la relación entre ciencia y sociedad, conocer las noticias de la actividad científica nacional e internacional, leer los suplementos de Ciencias de los diarios digitales y también visitar muestras de museos de ciencias en línea".

El capítulo 9, "Inglés y TIC", menciona las actividades con las TIC que los docentes proponen para acompañar a sus alumnos para que ellos sean capaces de leer, de escribir, de escuchar, de ver, de hablar y de colaborar. Por otra parte, invita a pensar en cómo establecer articulaciones con otras asignaturas e introduce el concepto de competencia global; se narra la experiencia de inclusión de las TIC al aula en una escuela de Avellaneda; se ofrecen consejos para integrar las TIC en las clases de forma significativa y una invitada describe cómo las TIC están presentes a la profesión del traductor.

Las TIC hablan otras lenguas en el capítulo 9. Inglés y TIC en el que Marta Libedinsky y Paula Pérez invitan desde el marco conceptual a expresarse en una lengua extranjera. Sumando a la experiencia: Las TIC nos comunican: del aula de Inglés al mundo, se intenta mostrar como la conciencia global puede ayudarnos a reinterpretar nuestra identidad y aporta al estudio de lo local.

El desafío que presenta el libro es el compromiso con los alumnos y la responsabilidad por el desarrollo profesional para mejorar la educación secundaria. El recorrido por los distintos capítulos muestran que las TIC nos solo vinieron para quedarse sino que constituyen una oportunidad para lograr nuevas configuraciones que apuntan a enseñar y aprender mejor.

Aurelia García Profesora de Inglés (UNLPam). Especialista en Evaluación (UNLPam). Diplomada Superior en Ciencias Sociales con Mención en Educación y Nuevas Tecnologías. Adjunta responsable de

"Seminario Optativo II - Tecnología de la información y de la Comunicación” de la Facultad de Ciencias Humanas de la UNLPam. aure.garcia09@gmail.com

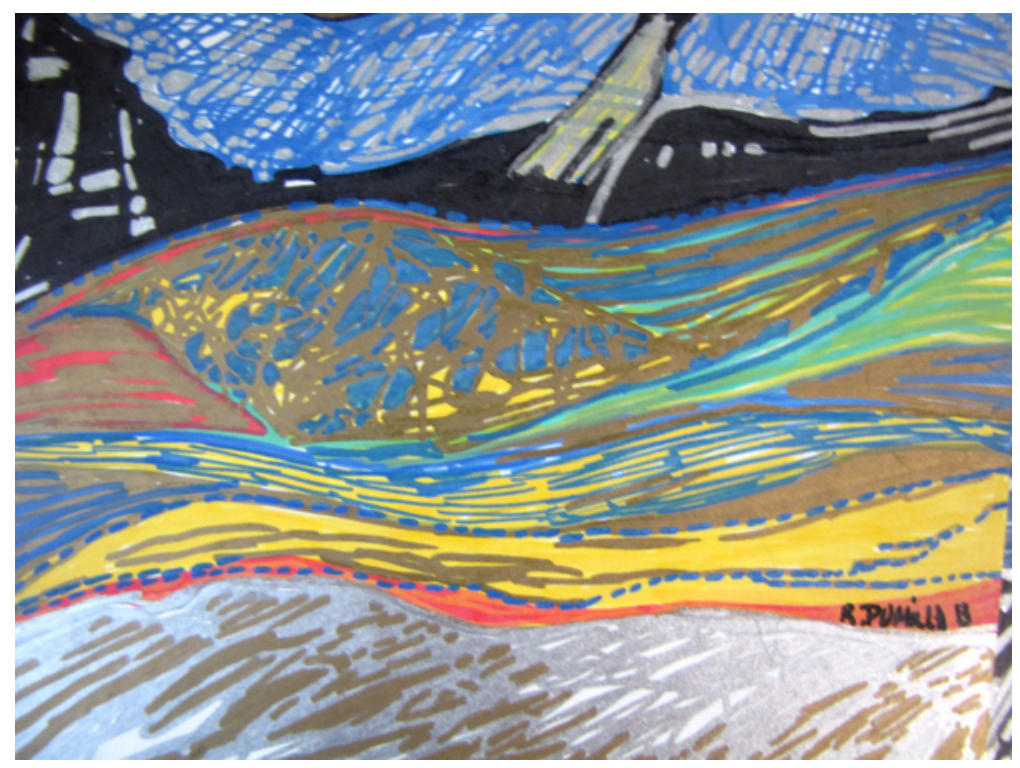

S/T, pintura. Raquel Pumilla 